\title{
Comentário
}

\section{Transtornos alimentares em discussão}

Passados quase dez anos do início dos primeiros grupos para o tratamento dos transtornos alimentares - anorexia e bulimia nervosas -, um olhar sobre a produção de pesquisa nacional oferece dados interessantes.

Ao estagiar no Instituto de Psiquiatria de Londres, em 1991, junto ao grupo de transtornos alimentares coordenado na época por Gerald Russell, um colega inglês sem constrangimento perguntou-me o que faria com meu treinamento, acreditando que os problemas alimentares brasileiros fossem a fome e a desnutrição.

Os quase 700 pacientes atendidos pelo Ambulatório de Bulimia e Transtornos Alimentares (Ambulim) do Instituto de Psiquiatria do HC-FM/USP desde 1992 e o desenvolvimento dos vários serviços pelo país desmentem o preconceito ainda vigente.

Estruturaram-se, além do Ambulim, o Proata na Unifesp, o Gota no Rio de Janeiro (Iede e UFRJ) e o grupo da Fundação Mário Martins - mais antigos e com maior produção científica. No momento, novos grupos iniciaram atendimento ou estão em fase de estruturação na Santa Casa do Rio de Janeiro, em Curitiba, Salvador, Fortaleza e na Unicamp.

Obesidade não é considerada um transtorno alimentar, mas os psiquiatras integraram-se no manejo de pacientes com esse problema, fazendo com que a obesidade "amigavelmente" fosse incorporada e estudada por esses grupos.

As limitações para pesquisa com transtornos alimentares no Brasil são grandes e pode-se dividi-las em: formação da equipe; custo do tratamento; interação entre pesquisadores; formação de orientadores; ausência de terapeutas comportamentais; e falta de investimentos.

Mais do que em outras áreas, o tratamento exige uma equipe multidisciplinar em que psiquiatra, endocrinologista, ginecologista, pediatra, terapeutas individual e familiar, nutricionista, enfermagem e eventualmente outros profissionais podem ser necessários.

Até o início dos anos 90, não havia qualquer nutricionista sistematicamente trabalhando com esses pacientes, ou qualquer treinamento específico de enfermagem.

A constituição da equipe, seu treinamento e a necessidade de uma enfermaria específica tornam o tratamento extremamente caro.

Os custos de hospitalização de uma paciente com anorexia nervosa foram orçados em US\$ 18.000 contra US\$ 11.000 para esquizofrenia, US\$ 10.000 para bulimia e US\$ 8.700 para depressão nos EUA (Vitiello \& Lederhendler, 2000). ${ }^{1}$

A interação e o envolvimento dos grupos que trabalham com transtornos alimentares no Brasil é pequena, seja entre si ou com neurocientistas de outras áreas.

Um passeio pelas publicações nacionais sobre binge eating disorder surpreende nomes tão diferentes como transtorno da compulsão alimentar periódica, transtorno da compulsão alimentar episódica, transtorno do comer compulsivo, transtorno do comer impulsivo, transtorno do descontrole alimentar episódico. Essa disparidade não constitui apenas uma nuança de tradução, mas uma especialidade que precisa de definições - compulsivo e impulsivo certamente são constructo teóricos muito diferentes.

Dado o pouco tempo de interesse na área, o número de doutores, peça fundamental para a formação de novos profissionais, ainda é muito pequeno.

Considerada essencial no tratamento, a psicoterapia cognitiva apenas recentemente cresceu no país, abrindo mais perspectivas terapêuticas e de pesquisa, uma vez que as psicoterapias psicodinâmicas dominantes no Brasil, em geral, não têm tradição em pesquisa.

A suposta raridade e a ausência de tratamento farmacológico têm afastado os investimentos das instituições de saúde e das indústrias farmacêuticas.

O primeiro preconceito não contempla dados epidemiológicos recentes; a anorexia nervosa afeta cerca de $0,5 \%$ das mulheres (crescendo entre homens), a bulimia nervosa, de $1 \%$ a $2 \%$, e o transtorno do comer compulsivo está presente em $2 \%$ a $3 \%$ da população geral (quase 30\% dos obesos em tratamento).

Provavelmente em função da melhor resposta farmacológica, há uma maior atenção farmacêutica na obesidade, e os investimentos nessa área são maiores.

A esses problemas "endógenos", somam-se as dificuldades de publicação internacional que prejudicam a interação com grupos do exterior. Nesse sentido, sugiro o artigo de Patel \& Sumathipala no British Journal Psychiatry, ${ }^{2}$ avaliando artigos de seis revistas de impacto em psiquiatria, entre 1996 e 1998, e determinando a origem dos 2.902 trabalhos publicados.

Cerca de 94\% dos trabalhos originaram-se nos Estados Unidos, na Europa Ocidental, na Austrália e na Nova Zelândia, e apenas $173(6 \%)$ no que os autores chamam de "Row": rest of the world.

As justificativas incluem: "revisores e editores julgam os artigos oriundos do 'Row' menos relevantes"; "leitores são menos interessados em artigos de países em desenvolvimento..."; “o valor científico (...) é menos importante (...)". Apesar de tudo, as expectativas são promissoras.

O crescente interesse pela área pôde ser visto no grande nú- 
mero de participantes do IV Encontro Brasileiro de Transtornos Alimentares e Obesidade (14 a 16 junho de 2001) na Unifesp/EPM, com o advento de profissionais de outras áreas, como odontólogos, terapeutas ocupacionais e historiadores.

Uma avaliação dos trabalhos brasileiros publicados sobre transtornos alimentares no Lilacs (Índex Medico LatinoAmericano) exibe um número crescente nos últimos dez anos, respondendo por cerca de $45 \%$ das publicações da América Latina.

Apesar das dificuldades, artigos de qualidade têm sido publicados na literatura internacional em revistas de grande impacto. ${ }^{3-5}$

Há dez anos raramente os cursos curriculares de psiquiatria incluiriam uma aula sobre transtornos alimentares, atualmente obrigatória. No momento, há pelo menos dez teses e dissertações em transtornos alimentares em andamento apenas nos programas de pós-graduação da Unifesp e da FM/USP.
Dois livros e dois manuais para familiares, além de inúmeros capítulos sobre transtornos alimentares em manuais de psiquiatria, endocrinologia e outras, surgiram nos últimos anos. ${ }^{6,7}$

Temos a certeza de que em Porto Alegre, quando do V Encontro Brasileiro de Transtornos Alimentares e Obesidade, em 2003, novos grupos de outros centros somar-se-ão em um evento de elevado nível científico.

\section{Agradecimentos}

A Jair Mari pelo apoio e sugestões preciosas.

Táki Athanássios Cordás Ambulatório de Bulimia e Transtornos Alimentares (Ambulim) do Instituto de Psiquiatria do Hospital das Clínicas e Departamento de Psiquiatria da Faculdade de Medicina da USP

\section{Referências}

1. Vitiello B, Lederhendler I. Research on eating disorders: current status and future prospects. Biol Psychiatry 2000:47:777-86.

2. Patel V, Sumathipala A. International representation in psychiatric literature. Br J Psychiatry 2001;178:406-9.

3. Appolinário JC, Coutinho W, Fontenelle L. Topiramate for bingeeating disorder. Am J Psychiatry 2001;158:966-7

4. Hay PJ, Bacaltchuk J. Psychotherapy for bulimia nervosa and binging (Cochrane Review). In: The Cochrane Library; 2001.

5. Pope HG, Mangweth B, Negrão AB, Hudson JI, Cordás T. Childhood sexual abuse, and bulimia nervosa. A comparison of american and brazilian women. Am J Psychiatry 1994;151:732-7.

6. Cordás TA. Bulimia nervosa: diagnóstico e propostas de tratamento. São Paulo (SP): Editora Lemos; 1998.

7. Cordás TA. Anorexia e bulimia: O que são? Como ajudar? $1^{\mathrm{a}}$ ed. Porto Alegre (RS): Editora Artes Médicas; 1998. 